\title{
PREVALENCE OF CORONARY ARTERY DISEASE IN PATIENTS WITH VALVULAR HEART DISEASE
}

\author{
Hiranya Kumar Saharia ${ }^{1}$, Rajita Devi
}

${ }^{1}$ Assistant Professor, Department of Anaesthesiology and Critical Care, Gauhati Medical College and Hospital, Guwahati. ${ }^{2}$ Lecturer, Medical Surgical Nursing, College of Nursing, Hayat Institute of Nursing Education, Hayat Hospital, Guwahati.

\begin{tabular}{l} 
ABSTRACT \\
\hline BACKGROUND \\
Heart disease is a growing problem, particularly in developing countries. India has quoted to have $12.2 \%$ and $12 \%$ prevalence of \\
coronary artery disease and rheumatic valvular heart disease respectively. Some older reports suggest that rheumatic fever, in \\
addition to producing specific injuries to small coronary arterial branches may accelerate the development of coronary \\
atherosclerosis.
\end{tabular}

AIM

To assess the prevalence of Coronary Artery disease in patients with Valvular Heart disease in some selected hospitals of Guwahati, Assam.

\section{SETTING AND DESIGN}

It was conducted in Gauhati Medical College and Hospital and Hayat Hospital, Guwahati. Explorative approach, survey design was selected for the study.

\section{MATERIALS AND METHODS}

Purposive sampling technique was used to select 126 patients who were diagnosed with valvular heart disease. Data was collected through a self-structured interview scheduled on prevalence of coronary artery disease.

\section{RESULTS}

Of the total 126 patients of valvular heart disease, 108 (85.71\%) cases were rheumatic valvular heart disease and 18 (14.29\%) were non-rheumatic valvular heart disease. Majority (56.34\%) of cases with CAD and RHD were in the range of 45 to 54 years. The prevalence of typical angina was significantly high among men (41.18\%). Most of the rheumatic patients (72.22\%) did not complain about angina. Diabetes mellitus, hypertension and dyslipidaemia are significantly high among non-rheumatic group and Coronary artery disease group. In our study, the overall prevalence of significant coronary artery disease in patients with valvular heart disease was $14.28 \%$.

\section{CONCLUSION}

Coronary artery disease prevalence is very high in this part of the country. Health professionals should actively participate in health promotion activities, apply the findings of the study to identify high risk individuals and prevent the occurrence of coronary artery disease.

\section{KEYWORDS}

Coronary Artery Disease, Rheumatic Heart Disease, Valvular Heart Disease, Risk Factors, Non-Rheumatic Heart Disease.

HOW TO CITE THIS ARTICLE: Saharia HK, Devi R. Prevalence of coronary artery disease in patients with valvular heart disease. J. Evolution Med. Dent. Sci. 2016;5(54):3599-3603, DOI: 10.14260/jemds/2016/829

\section{INTRODUCTION}

Heart disease is a growing problem particularly in developing countries. Most common among the heart diseases are coronary artery disease, valvular heart disease, rheumatic heart disease, etc. The overall prevalence of coronary artery disease with valvular heart disease in western world ranges from $14 \%$ to $29 \% .^{[1,2]}$ The prevalence of coronary artery disease with rheumatic heart disease in English literature

Financial or Other, Competing Interest: None.

Submission 29-04-2016, Peer Review 02-06-2016,

Acceptance 07-06-2016, Published 05-07-2016.

Corresponding Author:

Dr. Hiranya Kumar Saharia,

Assistant Professor,

Anaesthesiology and Critical Care,

Department of Emergency Medicine,

Gauhati Medical College and Hospital,

Guwahati.

E-mail: sahariahiranya@gmail.com

DOI: $10.14260 /$ jemds/2016/829 varies from $4 \%$ to $13 \%,{ }^{[3,4]}$ India has quoted to have $12.2 \%$ and $12 \%$ prevalence of coronary artery disease and rheumatic valvular heart disease respectively. ${ }^{[5,6]}$ There is prevalence of $33.61 \%$ Coronary artery disease among Non-Rheumatic Valvular Heart Disease patients in Brazil; whereas there has been no study on non-rheumatic valvular heart disease in India so far.[3]

Atherosclerosis of the coronary arteries is the commonest cardiac disorder in adults. Clinical evidence of this disorder occurs particularly after the age of 40 years, the age period when most patients are subjected to surgery for correction of valvular dysfunction and it is evident that rheumatic heart disease and coronary artery disease may coexist. Some older reports suggest that rheumatic fever, in addition to producing specific injuries to small coronary arterial branches, may accelerate the development of coronary atherosclerosis.[6]

Very little is known about the prevalence of coronary artery disease in patients with valvular heart disease in north east region of the country. So far there has not been any study 
conducted in this region about the prevalence of coronary artery disease in patients with valvular heart disease and this study would definitely help in health professionals to promote health.

\section{AIMS AND OBJECTIVES OF THE STUDY}

- To determine the overall prevalence of significant coronary artery disease in patients with valvular heart disease undergoing valve surgery.

- $\quad$ To determine the prevalence of coronary artery disease in Rheumatic valvular heart disease and non-rheumatic valvular heart disease separately.

- To identify the incidence of coronary artery disease in various forms of valve disease in isolation or in combination.

- $\quad$ To identify, if any clinical marker can predict coronary artery disease in valvular heart disease patients.

\section{MATERIALS AND METHODS}

An explorative approach, survey design was used in order to achieve the objectives of the study and it was conducted in Cardiology Department of Gauhati Medical College and Hospital and Hayat Hospital of Guwahati, Assam. The population comprised of patients with valvular heart disease and a total of 126 patients were selected through purposive sampling technique.

\section{Inclusion Criteria}

1. Patients with age $\geq 35$ years.

2. Postmenopausal women.

3. Patients with chest pain, objective evidence of ischaemia, history of coronary artery disease and coronary risk factors.

\section{Exclusion Criteria}

1. Patients undergoing emergency valve surgery for acute aortic regurgitation, aortic dissection or endocarditis with haemodynamic instability.

The tool is a self-structured interview schedule on prevalence of coronary artery disease in patients with valvular heart disease. It consisted of,

Section I: Assessing selected variables like age, sex, typical and atypical angina, distribution of valvular lesion in CAD and prevalence of CAD.

Section II: To assess the prevalence of risk factors of coronary artery disease like diabetes (Considered when fasting plasma glucose was $\geq 126 \mathrm{mg} / \mathrm{dL}$ or 2 -hour plasma glucose $\geq 200$ $\mathrm{mg} / \mathrm{dL}$ during oral glucose tolerance test or HbA1C $>6.5$ or random blood glucose $\geq 200 \mathrm{mg} / \mathrm{dL}$ with symptoms of diabetes), hypertension (Considered systolic arterial pressure $\geq 140 \mathrm{mmHg}$ or diastolic arterial pressure $\geq 90 \mathrm{mmHg}$ or use of anti-hypertensive medication), dyslipidaemia (Considered when total cholesterol was $\geq 200 \mathrm{mg} / \mathrm{dL}$, triglycerides $\geq 150$ $\mathrm{mg} / \mathrm{dL}$ and HDL-C $\leq 40$ in men or $\leq 50$ in women) and smoking history and past or current drug treatment.

Section III: To assess the clinical characteristics of patients with coronary artery disease.
The reliability of the tool was calculated using split half method and it was found to be 0.71 . The study was conducted after receiving approval from the head of the institutes. The verbal and written consent was obtained from all the participants.

After formal permission was obtained from concerned authorities of both the institutes, the main study was conducted in the Cardiology Department of both the hospitals from December 2014 to July 2015; 126 consecutive cases of valvular heart disease who were scheduled for valve surgery were taken for the present study.

The patients were divided into three groups based on valve involvement (Mitral valve, aortic valve and combined aortic and mitral valve). Purpose of the study was explained and confidentiality of the responses was assured. Informed written consent was taken from participants. The items in the tool were found to be clear and unambiguous.

\section{RESULTS \\ Distribution of Samples on Selected Variables Age and Sex}

Out of 126 consecutive valvular disease cases, 108 cases were rheumatic valvular heart disease (85.71\%) and 18 were nonrheumatic valvular heart disease (14.29\%). Majority of cases were in the range of 45 to 54 years. Sixty eight (53.96\%) were males and 58 (46.04\%) were females with male-to-female ratio of 1.17:1. In rheumatic valvular heart disease, males and females were equal with ratio of 1:1. In non-rheumatic valvular heart disease, males outnumbered females with the ratio of 3.5:1. In rheumatic group, most of the males (51.85\%) and females $(77.78 \%)$ were between 45 to 54 years of age group. In non-rheumatic group, most of the males and females were in the 55 to 64 years of age group with higher mean age in females (63.05 years vs 59.56 years, $p=0.024$ ) [Table 1].

\section{Distribution of Angina according to Sex}

In this study among total population typical angina was noted in $29.36 \%$ of patients, while there were no angina in $62.69 \%$ of cases. The prevalence of typical angina was high among men (41.18\%) compared to women (15.51\%), while atypical angina was more common among females (13.79\%) than males (2.94\%). Absent angina was high in women (70.69\%) than men (55.58\%) [Figure 1].

\section{Distribution of Angina across type of Valvular Heart Disease}

Majority of cases $(70.83 \%)$ with typical angina was present in aortic valve lesion. In mitral valve disease, majority of patients (87.5\%) presented with no angina. In combined lesion (Mitral + aortic), 52.63\% patients presented with no angina [Figure 2] Most of the rheumatic patients did not complain about angina, while typical and atypical angina were common complaint in non-rheumatic group [Figure 3].

Coronary artery disease group had significantly high frequency of typical and atypical angina $(p=0.001)$, while angina was significantly absent in patients without coronary artery disease $(\mathrm{p}=0.001)$ [Figure 4 ].

In our study $50.79 \%$ had isolated mitral valve disease, $19.05 \%$ were isolated aortic valve disease and combined mitral and aortic valve lesion were present in $30.16 \%$ of patients. Isolated mitral valve disease was more common in women $(p=0.002)$, while isolated aortic valve disease in men 
$(\mathrm{p}=0.001)$. Combined mitral and aortic valve disease was almost equal in frequency in both groups $(\mathrm{p}=0.561)$.

\section{Prevalence of Risk Factors of Coronary Artery Disease}

Of the total patient's population diabetes mellitus were present in $9.52 \%$ of patients, $19.05 \%$ were hypertensive, dyslipidaemia was found in $25.39 \%$ of cases and $47.61 \%$ of patients were current or ex-smoker. Atrial fibrillation was present in $39.68 \%$ of population.

Coronary artery disease group has significantly high prevalence of diabetes mellitus, hypertension and dyslipidaemia ( $p$ value of $<0.001$ for each); it was insignificant for smoking $(p=0.081)$. Atrial fibrillation was insignificantly associated with coronary artery disease $(\mathrm{p}=0.102)$.

Mitral valve disease is significantly more common in patients without coronary artery disease $(\mathrm{p}<0.001)$, while aortic valve lesion is significantly more in coronary artery disease group $(\mathrm{p}=0.003)$. Combined valve lesion is insignificantly high among patients with coronary artery disease $(p=0.154)$.

Coronary artery disease was significantly more common among non-rheumatic valvular heart disease (44.44\%) in comparison to rheumatic valvular heart disease (9.26\%) patients $(\mathrm{p}<0.001)$. Prevalence of coronary artery disease was high among males (17.64\%) in comparison to females (10.34\%). Overall frequency of coronary artery disease among mitral, aortic and combined mitral and aortic valve lesion is $3.13 \%, 33.33 \%$ and $21.05 \%$ respectively. In comparison to mitral valve disease, aortic valve disease and combined lesion having significantly high chances of coronary artery disease $(\mathrm{p}=0.001)$. In our study, total 18 patients had coronary artery disease; out of them 14 had single vessel disease, 2 had double vessel disease and 2 had left main disease. None of the patients had triple vessel disease [Table 2].

\section{Clinical Characteristics of Patients with Coronary Artery Disease}

The study reported that mean age of the patients with coronary artery disease $(59.45 \pm 10.58)$ are significantly high in comparison to without coronary artery disease (48.92 \pm 6.57$)$. Among coronary artery disease group $66.67 \%$ were male, $33.33 \%$ were females; while among without coronary artery disease group male and female were $51.85 \%$ and $48.15 \%$ respectively (p=0.243) [Table 3].

\begin{tabular}{|c|c|c|c|c|}
\hline Rheumatic & Total & Male & Female & P value \\
\hline $\mathrm{N}$ & 108 & 54 & 54 & 0.653 \\
\hline Mean age (Years) & 48.87 & 49.10 & 48.64 & 0.856 \\
\hline $35-44$ years & $18(16.66 \%)$ & $16(29.62 \%)$ & $2(3.70 \%)$ & \\
\hline $45-54$ years & $69(63.88 \%)$ & $28(51.85 \%)$ & $42(77.78 \%)$ & \\
\hline $55-64$ years & $16(14.81 \%)$ & $8(14.81 \%)$ & $8(14.81 \%)$ & \\
\hline$\geq 65$ years & $4(3.70 \%)$ & $2(3.70 \%)$ & $2(3.70 \%)$ & P value \\
\hline Non-Rheumatic & Total & Male & 14 & 0.029 \\
\hline $\mathrm{N}$ & 18 & 59.56 & 63.05 & 0 \\
\hline Mean age (Years) & 60.94 & $1(7.14)$ & 0 & \\
\hline 35-44 years & $1(5.56 \%)$ & $1(7.14 \%)$ & $2(50 \%)$ & \\
\hline 45-54 years & $1(5.56 \%)$ & $8(57.14 \%)$ & $2(50 \%)$ & \\
\hline$\geq 65$ years & $10(55.56 \%)$ & $4(28.57 \%)$ & & \\
\hline
\end{tabular}

$\mathrm{N}=$ number

\begin{tabular}{|c|c|c|c|c|c|c|c|}
\hline Variables & Total & Male & Female & Rheumatic & Non-Rheumatic & No CAD & CAD \\
\hline DM & $12(9.52)$ & $10(14.71)$ & $2(3.45)$ & $6(5.56)$ & $6(33.33)$ & $6(5.56)$ & $6(33.33)$ \\
\hline HTN & $24(19.05)$ & $14(20.58)$ & $10(17.24)$ & $14(12.96)$ & $10(55.56)$ & $14(12.96)$ & $10(55.56)$ \\
\hline Dyslipidaemia & $32(25.39)$ & $14(20.58)$ & $18(31.03)$ & $22(20.37)$ & $10(55.56)$ & $20(18.52)$ & $12(66.67)$ \\
\hline Smoking & $60(47.61)$ & $54(79.41)$ & $6(10.34)$ & $48(44.44)$ & $12(66.67)$ & $48(44.44)$ & $12(66.67)$ \\
\hline AF & $50(39.68)$ & $24(35.29)$ & $26(44.83)$ & $50(46.29)$ & 0 & $46(42.59)$ & $4(22.22)$ \\
\hline \multicolumn{7}{|c|}{ Table 2: Prevalence of Risk Factors of Coronary Artery Disease } \\
\hline
\end{tabular}

$\%$ given in parenthesis

DM=Diabetes Mellitus, HTN=Hypertension, AF=Atrial Fibrillation, CAD=Coronary Artery Disease.

\begin{tabular}{|c|c|c|c|c|c|}
\hline Variables & No CAD & \% & With CAD & \% & P value \\
\hline Age (Mean) & $48.92 \pm 6.57$ & & $59.45 \pm 10.58$ & 0.001 \\
\hline Male & 56 & 51.85 & 12 & 66.67 & 0.243 \\
\hline Female & 52 & 48.15 & 6 & 33.33 & 0.234 \\
\hline Typical Angina & 25 & 23.15 & 12 & 66.67 & 0.001 \\
\hline Atypical Angina & 7 & 6.48 & 3 & 16.67 & 0.074 \\
\hline No Angina & 76 & 70.37 & 3 & 16.67 & 0.001 \\
\hline Mitral Disease & 62 & 57.41 & 2 & 11.11 & $<0.001$ \\
\hline Aortic Disease & 16 & 14.81 & 8 & 44.44 & 0.003 \\
\hline Combined Lesion & 30 & 27.78 & 8 & 44.44 & 0.154 \\
\hline Rheumatic Aetiology & 98 & 90.74 & 10 & 55.56 & 0.001 \\
\hline Non-Rheumatic Aetiology & 10 & 9.26 & 8 & 44.44 & 0.001 \\
\hline \multicolumn{7}{|c|}{ Table 3: Clinical Characteristics of CAD and No CAD Population } \\
\hline
\end{tabular}

CAD=Coronary Artery Disease 


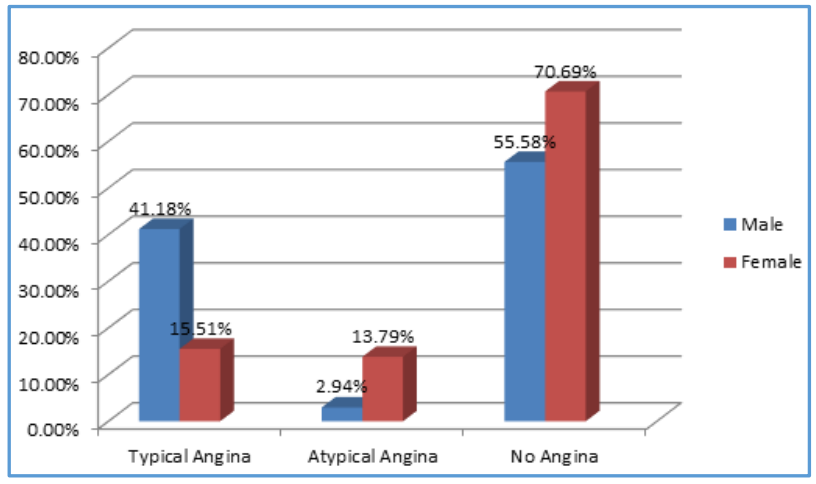

Fig. 1: Distribution of Angina according to Sex

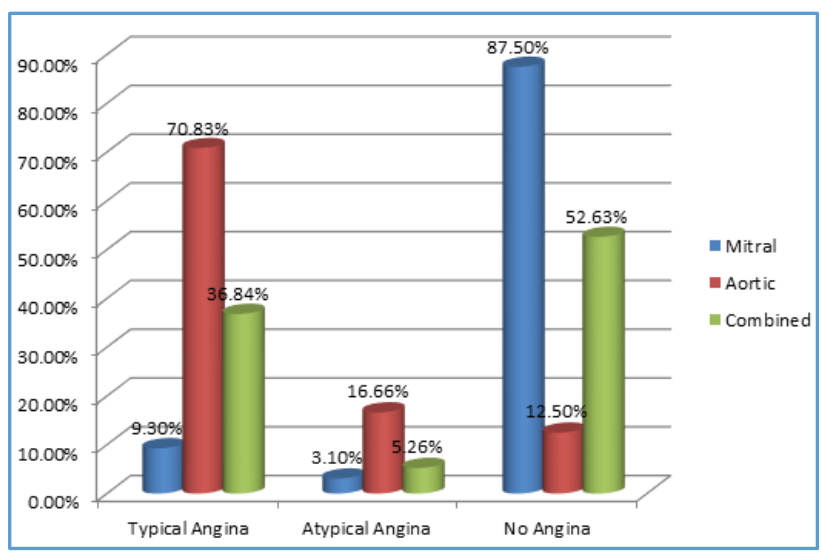

Fig. 2: Distribution of Angina in Different Valve Lesions

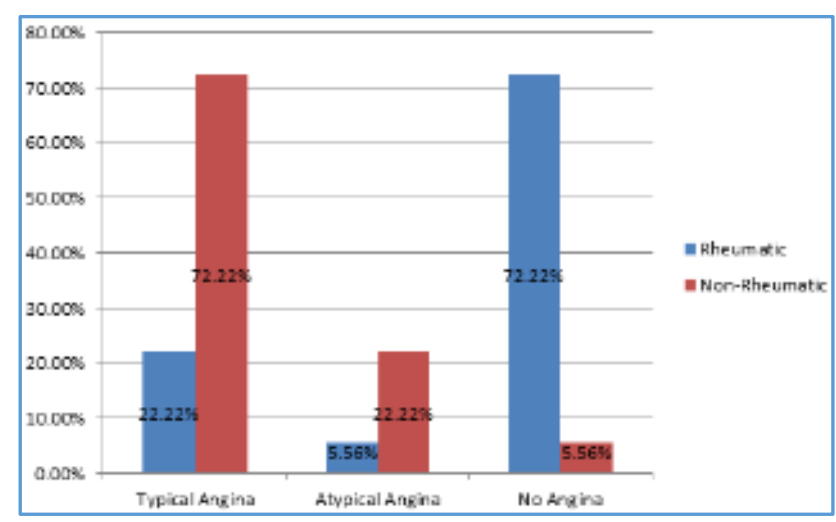

Fig. 3: Distribution of Angina in Rheumatic and Non-Rheumatic Group

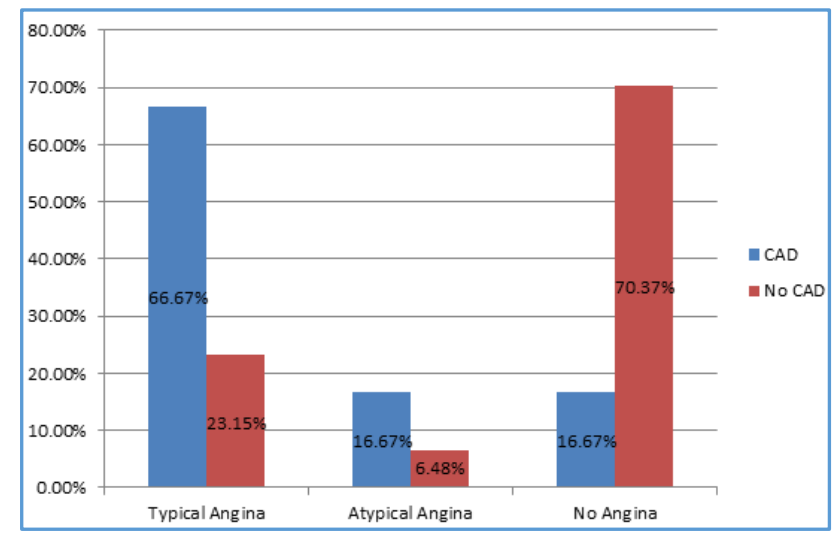

Fig. 4: Distribution of Angina in CAD and No CAD Group $\mathrm{CAD}=$ Coronary Artery Disease

\section{DISCUSSION}

A total of 126 consecutive patients of valvular heart disease going for valve replacement surgery in some selected hospitals of Guwahati were studied from December 2014 to July 2015 to find out the prevalence of coronary artery disease.

Available literature related to valvular heart disease and its association with coronary artery disease was reviewed as far as possible.

It has been observed that of the total 126 patients of valvular heart disease, $108(85.71 \%)$ cases were rheumatic valvular heart disease and $18(14.29 \%)$ were non-rheumatic valvular heart disease. Majority (56.34\%) of cases were in the range of 45 to 54 years, so also with rheumatic heart disease group, but majority of non-rheumatic group were between 55 to 64 years. Of the total population, $53.96 \%$ were males and $46.04 \%$ were females with male-to-female ratio of 1.17:1. The findings corroborates with a study by Kruczan et al[3], the mean age of total population was 54 years, while of those with rheumatic valvular disease had 50.87 in comparison to 63.66 years in non-rheumatic.

Typical angina was noted in $29.36 \%$ of patients, atypical angina in $7.93 \%$ and $62.69 \%$ of cases have no history of angina. The prevalence of typical angina was significantly high among men (41.18\%); atypical angina (13.79\%) and absent angina $(70.69 \%)$ was significantly more common among females. Typical angina was most common presentation in aortic valve lesion in $70.83 \%$, while absent angina was commonest presentation in mitral valve disease (87.5\%) and in combined mitral and aortic lesion (52.63\%).

More than three quarter of coronary artery disease group had history of typical (66.67\%) and atypical angina (16.67\%), while absent angina (70.37\%) was predominant in patients without coronary artery disease. Similar findings were noted in a study by Hancock EW et al[7] where angina was noticed in $45 \%$ of cases and significant coronary lesion was present in $64 \%$ of patients with angina and $33 \%$ without angina.

Diabetes mellitus, hypertension and dyslipidaemia are significantly high among non-rheumatic group. Nonrheumatic group had more smokers $(\mathrm{p}=0.081)$. All atrial fibrillation patients were rheumatic. Coronary artery disease group had significantly high prevalence of diabetes mellitus, hypertension and dyslipidaemia. The history of smoking was insignificantly more in coronary artery disease group. The findings are supported by study conducted by Jose VJ et al[5], where it was noted that hypertension was found in $23.4 \%$ patients, diabetes in $17.3 \%$, smoking in $26.1 \%$ and dyslipidaemia in $17.6 \%$ and past history of myocardial infarction in $4.0 \%$ patients.

Mitral valve (59.26\%) was most commonly affected valve in rheumatic valvular heart disease. All patients of nonrheumatic group had isolated aortic valve lesion. This is supported by a study conducted by Baxter $\mathrm{RH}$ et al[8] that angina in mitral valve disorders is thus much more likely to be the result of disease of the coronary arteries.

In our study, the overall prevalence of significant coronary artery disease in patients with valvular heart disease was $14.28 \%$. The prevalence of significant coronary artery disease in rheumatic heart disease was $9.26 \%$. In non-rheumatic valvular disease, it was significantly high with prevalence of $44.44 \%$. Mitral valve disease $(57.41 \%$ vs $11.11 \%)$ is significantly more common in patients without coronary artery disease; while aortic valve lesion ( $44.44 \%$ vs $14.81 \%)$ 
is significantly more in coronary artery disease group. Combined valve lesion is insignificantly high among patients with coronary artery disease $(\mathrm{p}=0.154)$. The findings are supported by Morrison GW et al[2], Chun et al[9] and Marchant E et al.[1]

Mean age of the patients with coronary artery disease (59.45 \pm 10.58 ) was significantly high in comparison to without coronary artery disease $(48.92 \pm 6.57)$. This is supported by a retrospective study by Gupta KG et al[10], where the mean age of the patients with significant coronary artery disease was $54.5 \pm 6.6$ years as against a mean age of $49 \pm 7.5$ years for those without coronary artery disease $(\mathrm{p}<0.01)$.

Prevalence of coronary artery disease was insignificantly high among males (17.64\%) in comparison to females (10.34\%). Similar findings were noted in a Turkish study by Sonmez K et al[11], where it was found that prevalence of significant coronary artery disease in $24 \%$ of males and $9 \%$ of females $(p<0.001)$.

Among the mitral valve disease patients, typical angina was present in $9.3 \%$ of the patients, of whom $33.33 \%$ had significant coronary artery disease and none of the patients had coronary artery disease in no angina group; among the isolated aortic valve disease typical angina was present in $70.83 \%$ of patients and of whom only $23.52 \%$ had significant coronary artery disease. Overall, prevalence of coronary artery disease among mitral, aortic and combined mitral and aortic valve lesion is $3.13 \%, 33.33 \%$ and $21.05 \%$ respectively. In comparison to mitral valve disease, aortic valve disease and combined lesion have significantly higher chance of coronary artery disease $(\mathrm{p}=0.001)$. The findings are supported by Moraski RE et al[12] and Lacy J et al.[13]

\section{CONCLUSION}

Overall prevalence of significant coronary artery disease in patients with valvular heart disease is $14.28 \%$ in this part of the country. Prevalence of coronary artery disease in rheumatic valvular heart disease is $9.26 \%$, while in nonrheumatic valvular heart disease it is $44.44 \%$. Angina is often not associated with coronary artery disease, while coronary artery disease can be present in the absence of angina.

This study aims to find out the prevalence of coronary artery disease in patients with valvular heart disease and the prevalence of risk factors. Coronary artery disease prevalence is very high in this part of the country. So, the health professionals should actively participate in health promotion activities, apply the findings of the study to identify high risk individuals and prevent the occurrence of coronary artery disease.

\section{REFERENCES}

1. Marchant E, Pichard A, Casanegra P. Association of coronary artery disease and valvular heart disease in Chile. Clin Cardiol 1983;6(7):352-6.

2. Morrison GW, Thomas RD, Grimmer SF, et al. Incidence of coronary artery disease in patients with valvular heart disease. Br Heart J 1980;44(6):630-7.

3. Kruczan DD, Silva NA, Pereira Bde B, et al. Coronary artery disease in patients with rheumatic and non-rheumatic valvular heart disease treated at a public hospital in rio de Janeiro. Arq Bras Cardiol 2008;90(3):197-203.

4. Coleman EH, Soloff LA. Incidence of significant coronary artery disease in rheumatic valvular heart disease. The American Journal of Cardiology 1970;25:401-4.

5. Jose VJ, Gupta SN, Joseph G, et al. Prevalence of coronary artery disease in patients with rheumatic heart disease in the current era. Indian Heart J 2004;56(2):129-31.

6. Ranganathan A, Sangareddi V, Swaminathan N. Prevalence of coronary artery disease in patients with rheumatic heart disease-why discordant? Ind heart J 2012;64:s11.

7. Hancock EW. Aortic stenosis, angina pectoris, and coronary artery disease. Am Heart J 1977;93(3):382-93.

8. Baxter RH, Reid JM, McGuiness JB, et al. Relation of angina to coronary artery disease in mitral and aortic valve disease. Br Heart J 1978;40(8):918-22.

9. Chun PK, Gertz E, Davia JE, et al. Coronary atherosclerosis in mitral stenosis. Chest 1982;81(1):36-41.

10. Gupta KG, Loya YS, Bhagwat AR, et al. Prevalence of significant coronary heart disease in valvular heart disease in Indian patients. Ind Heart J 1990;42(5):357-9.

11. Sonmez K, Gencbay M, Akcay A, et al. Prevalence and predictors of significant coronary artery disease in Turkish patients who undergo heart valve surgery. J Heart Valve Dis 2002;11(3):431-7.

12. Moraski RE, Russell RO, Mantle JA, et al. Aortic stenosis, angina pectoris, coronary artery disease. Cathet Cardiovasc Diagn 1976;2(2):157-64.

13. Lacy J, Goodin R, McMartin D, et al. Coronary atherosclerosis in valvular heart disease. Ann Thorac Surg 1977;23(5):429-35. 